\title{
A Virus from Epidemic Vomiting Disease
}

\author{
S. K. R. CLARKE, \\ D. RUBENSTEIN, \\ G. T. COOK, \\ A. J. SMITH, \\ S. I. EGGLESTONE, T. S. HALL, \\ D. L. MILLER, \\ S. E. REED, \\ D. A. J. TYRRELL
}

British Medical fournal, 1972, 3, 86-89

\begin{abstract}
Summary
An illness consisting of vomiting, fever, and mild diarrhoea after a short incubation period was observed in a boarding school and reproduced in volunteers who received filtered extracts of faeces from a typical case. The main discriminatory diagnostic feature of the illness in volunteers was vomiting. The faeces contained no pathogenic bacteria nor any virus that could be detected in tissue cultures and there was no evidence that an infective agent could be grown in organ cultures of human intestine. The agent was shown to be ether stable and passed a 50-nm filter. Laboratory studies on another agent of uncertain significance and obtained in other epidemics are briefly described.
\end{abstract}

\section{Introduction}

Winter vomiting disease was described in the Southern U.S.A. as an illness affecting families, in which a short, self-limiting bout of vomiting with some diarrhoea was the main feature. Subsequent study has confirmed that the illness represents an entity distinct from bacterial gastroenteritis, and this is particularly clear in institutional outbreaks when cultures consistently negative for pathogenic bacteria are obtained. A disease of this type has been reproduced by giving material from a family outbreak to volunteers (Jordan et al., 1953). A more severe febrile gastroenteritis was produced with material from an epidemic in a mental hospital.

TABLE I-Preliminary Volunteer Experiments Carried Out in Bristol using Material from Epidemics of Winter Vomiting Disease

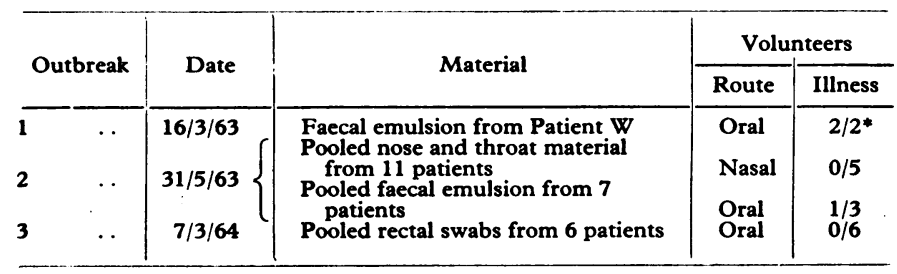

*These two volunteers are included in Tables II and III.

Public Health Laboratory, Kingsdown, Bristol

S. K. R. CLARKE, M.D., F.R.C.PATH., Consultant Virologist

S. I. EGGLESTONE, PH.D., Scientific Officer

Public Health Laboratory, Guildford, Surrey

G. T. COOK, M.D., F.R.C.PATH., Director (retired)

A. J. SMITH, F.I.M.L.T., Chief Technician

Central Public Health Laboratory, Colindale, London N.W.9

D. L. MILLER, M.D., D.P.H., Deputy Director, Epidemiological Research Laboratory (At present Professor of Community Medicine, the Middlesex Hospital Medical School, London W.1)

Clinical Research Centre, Harrow, Middlesex

D. RUBENSTEIN, M.D., M.R.C.P., Clinical Research Fellow

D. A. J. TYRRELL, M.D., F.R.C.P., F.R.S., Head of Division of Communicable Diseases

Clinical Research Centre, Salisbury, Wilts.

T. S. HALL, M.D., D.P.H., Medical Superintendent, M.R.C. Common Cold Unit

S. E. REED, M.B., B.CHIR., Member of Scientific Staff, M.R.C. Common Cold Unit
The present study was initiated to characterize the aetiological agent of an outbreak of epidemic vomiting in Britain in 1963.

In 1963 and 1964 material was collected from outbreaks of non-bacterial gastroenteritis by the Public Health Laboratory Service Working Party on Non-bacterial Gastroenteritis. Material from three outbreaks in closed communities was given to volunteers. This work is summarized in Table I. Material from outbreak No. 1 was selected for further study.

\section{The outbreak}

The boys' boarding school involved had 830 pupils aged 13 to 18 years. A few boys were sick on 14 and 15 March 1963 and about 50 boys were affected on 16 March. A further wave occurred on 18 and 19 March, which continued until the 22nd, when 142 pupils had been ill. Only one teacher and one of the kitchen staff were affected, both at the same time as the main wave in the boys. The attack rate was higher in the younger than in the older boys. Epidemiological inquiries failed to produce clear evidence of the mode of spread, but it seemed probable that the illness was transmitted by person-to-person contact and that the incubation period was only one to two days.

\section{The specimen}

Faeces were obtained from a boy (W) admitted on 18 March with sudden onset of diarrhoea (four loose motions) and fever to $99 \cdot 8^{\circ} \mathrm{F}\left(37.7^{\circ} \mathrm{C}\right)$. The next day he had recovered. The specimen of fluid faeces was stored at $-70^{\circ} \mathrm{C}$. Routine cultures showed no salmonellae, shigellae, Staphylococcus aureus, Clostridium welchii, or specific Escherichia coli and there was no evidence of growth of virus in suckling mice, in HeLa cells, in monkey kidney cells, or in cultures of WI-38 cells maintained at 33 or $37^{\circ} \mathrm{C}$ with or without serum. Faeces were emulsified in nine volumes of Eagle's medium containing antibiotics (sometimes with added $1 \%$ bovine plasma albumin), clarified by centrifugation at 3,000 r.p.m. to remove bacteria, and stored at $-70^{\circ} \mathrm{C}$ until required. This material was sterile on bacteriological culture.

\section{Volunteers}

The volunteers were either members of the staff of the Public Health Laboratory, Bristol, who were not kept in isolation or specially recruited volunteers isolated at the Common Cold Unit, Salisbury. They were of both sexes, and aged from 18 to 50 years. After initial experiments all the inoculations and clinical observations were conducted "blind." Volunteers inoculated at Salisbury received $500 \mathrm{mg}$ of human gammaglobulin intramuscularly at the end of the period of observation.

\section{Production of experimental illness}

Volunteers were given about $4 \mathrm{~g}$ of sodium bicarbonate in water by mouth, followed by the faecal emulsion which was added to a small glass of orange squash. As shown in Table II, lines $\mathrm{A}$ and $\mathrm{B}$, this inoculation was often followed by an illness which showed features resembling those seen in the epidemic. Faeces from the first three volunteers who became ill were 
TABLE II-Clinical Observations on Volunteers and Their Value in Discriminating between Inoculated and Control Subjects

\begin{tabular}{|c|c|c|c|c|c|c|c|c|c|c|c|}
\hline \multirow[b]{2}{*}{ Material Given } & \multirow{2}{*}{$\begin{array}{l}\text { No. of } \\
\text { Volunteers } \\
\text { Inoculated }\end{array}$} & \multicolumn{10}{|c|}{ No. showing Indicated Symptom(s) or Sign(s) } \\
\hline & & $\begin{array}{c}\text { Abdominal } \\
\text { Dis- } \\
\text { comfort }\end{array}$ & Nausea & $\begin{array}{l}\text { Diarrhoea (D) } \\
1 \text { or more Loose } \\
\text { Motions Daily }\end{array}$ & $\begin{array}{c}\text { Fever }(\mathrm{F}) \\
99 \cdot 4^{\circ} \mathrm{F}\left(37 \cdot 4^{\circ} \mathrm{C}\right) \\
\text { or more }\end{array}$ & $\begin{array}{l}\text { Vomiting } \\
\text { (V) Once } \\
\text { or more }\end{array}$ & $\begin{array}{l}\text { D or } \\
\text { Vor } \\
\text { F }\end{array}$ & $\mathbf{D}+\mathbf{F}$ & $\mathbf{V}+\mathbf{F}$ & $\mathbf{V}+\mathrm{D}$ & $\mathbf{D}+\mathrm{V}+\mathrm{F}$ \\
\hline $\begin{array}{l}\text { A. Untreated faecal } \\
\text { extracts } \\
\text { B. Treated faecal } \\
\text { extracts* }\end{array}$ & $\begin{array}{l}11 \\
15\end{array}$ & $\begin{array}{r}8 \\
13 \\
\end{array}$ & $\begin{array}{l}8 \\
9 \\
\end{array}$ & $\begin{array}{l}7 \\
5 \\
\end{array}$ & $\begin{array}{l}6 \\
6 \\
\end{array}$ & $\begin{array}{r}7 \\
10 \\
\end{array}$ & $\begin{array}{l}10 \\
11 \\
\end{array}$ & $\begin{array}{l}4 \\
2 \\
\end{array}$ & $\begin{array}{l}5 \\
6 \\
\end{array}$ & $\begin{array}{l}5 \\
4\end{array}$ & $\begin{array}{l}4 \\
3\end{array}$ \\
\hline Total A $+\mathbf{B}$ & 26 & 21 & 17 & 12 & 12 & 17 & 21 & 6 & 11 & 9 & 7 \\
\hline $\begin{array}{l}\text { C. Non-infectious } \\
\text { control fluids } \\
\text { D. Fluids from inoculated } \\
\text { organ cultures }\end{array}$ & $\begin{array}{l}12 \\
20\end{array}$ & $\begin{array}{l}3 \\
5\end{array}$ & $\begin{array}{l}2 \\
1\end{array}$ & $\begin{array}{l}2 \\
5\end{array}$ & $\begin{array}{l}1 \\
1\end{array}$ & $\begin{array}{l}0 \\
1\end{array}$ & $\begin{array}{l}2 \\
5\end{array}$ & $\begin{array}{l}1 \\
1\end{array}$ & $\begin{array}{l}0 \\
0\end{array}$ & $\begin{array}{l}0 \\
1\end{array}$ & $\begin{array}{l}0 \\
0\end{array}$ \\
\hline
\end{tabular}

*These extracts had been subjected to the various treatments shown in Table III.

negative for salmonellae, shigellae, specific $E$. coli, Staph. aureus, and $\mathrm{Cl}$. welchii.

It was thought that the illness might be due to a toxin present in the faecal extract. Therefore the emulsion was centrifuged at 6,000 r.p.m. for one hour and the supernatant fluid was recentrifuged at 35,000 r.p.m. for two hours. The deposit from this second cycle of centrifugation produced disease in one volunteer, and it was concluded that the activity was probably in a particle.

We wondered whether the agent could be serially propagated in man. Accordingly an emulsion was prepared as before from faeces collected eight hours after the onset of illness in a volunteer (C) who had diarrhoea. The emulsion was shown to be free from bacteria and from viruses when tested as described above. This emulsion produced definite illness, with vomiting, in three out of four volunteers to whom it was given. This serial propagation suggested the presence of an infective agent.

\section{Clinical Pattern of the Experimental Illness}

Although routine inquiries were made most volunteers had negligible symptoms referable to the respiratory tract, though two of the 26 volunteers who received faecal extracts showed typical symptoms of a cold in addition to definite gastrointestinal illness. However, in these two volunteers the earliest respiratory symptoms started respectively 29 hours before and 22 hours after inoculation of faecal emulsion, and it seems unlikely that the respiratory symptoms were the result of this inoculation.

In volunteers inoculated with faecal extracts the incubation period of gastrointestinal illness ranged from 15 to 58 hours with a median of 30 hours. The onset was often sudden and sometimes at night. Nausea usually preceded vomiting and the vomiting was at times profuse and associated with straining and retching. The diarrhoea was usually slight, and sometimes amounted to no more than soft or semi-fluid faeces which were rarely watery and never bloody. There was some griping with the diarrhoea, but the commonest abdominal symptom was a feeling of distension. Some inoculated volunteers who had no frank diarrhoea or vomiting, and also some others given control fluids, passed excessive flatus by mouth or by rectum. Fever and muscular aching were observed in some volunteers but were not a striking feature of the disease, although occasionally they were the only signs of infection-the temperature recorded ranged from 99.4 to $103^{\circ} \mathrm{F}\left(37.4\right.$ to $\left.39.4^{\circ} \mathrm{C}\right)$ with a median of $100^{\circ} \mathrm{F}\left(37 \cdot 8^{\circ} \mathrm{C}\right)$. Only seven of the 26 volunteers inoculated with faecal extracts showed the full syndrome of fever, vomiting, and diarrhoea. During the acute phase of the illness the volunteers often retired to bed for a few hours during the day. They looked pale and lacking in vitality, but then recovered rapidly.

Table II, lines A, B, and C, show that of the five major symptoms and signs, abdominal discomfort was very frequent, but unreliable in distinguishing inoculated subjects from controls who received diluent only. Nausea and diarrhoea were less frequent and were also of little discriminatory value since they occurred in control subjects. However, volunteers given control fluids never had more than three loose motions in one day whereas two of those given treated extracts and three of those given untreated extracts had four or more motions. One volunteer given faecal extract had seven diarrhoea motions but did not vomit. Fever was a better discriminator than diarrhoea, but vomiting was best: it occurred in 17 out of 26 given faecal extracts and in none out of 12 given control fluids. The control fluids were either nutrient broth, or Eagle's medium $+1 \%(w / v)$ bovine albumin, or fluids harvested from uninoculated organ cultures. Consequently, a volunteer could be regarded as having a specific illness if he vomited, since combinations of symptoms gave no better separation between the groups than this single criterion. Vomiting was therefore used as the criterion of infection in interpreting the results of the experiments described below.

\section{Some Characteristics of the Infectious Agent W}

Faeces from a case (W) occurring in the original epidemic were thawed after seven-and-a-half years of storage at $-70^{\circ}$. Emulsion prepared from this specimen produced typical illness in volunteers, and so also did faeces from a volunteer who had been given the original faecal extract, when an emulsion was prepared after storage of the specimen at $-70^{\circ} \mathrm{C}$ for seven years. As shown in Table III various amounts of faecal extracts were administered to volunteers. The smallest amount given, an extract of $0.005 \mathrm{ml}$ of faeces, produced a definite illness.

In order to obtain some idea of the way in which this agent might be classified, faecal extract was passed through filters of various porosities and was subjected to ether treatment. Table III shows that faecal extract diluted 1 in 5 and held at $4^{\circ} \mathrm{C}$ overnight with $20 \%(\mathrm{v} / \mathrm{v})$ ethyl ether produced typical disease. Table III also shows results obtained with faecal extracts which had been passed through Millipore filters of pore diameters $220 \mathrm{~nm}, 100 \mathrm{~nm}$, or $50 \mathrm{~nm}$. All the filtrates produced typical illness in volunteers.

TABLE III-Effect of Various Treatments on Infectivity of Faecal Extracts for Volunteers

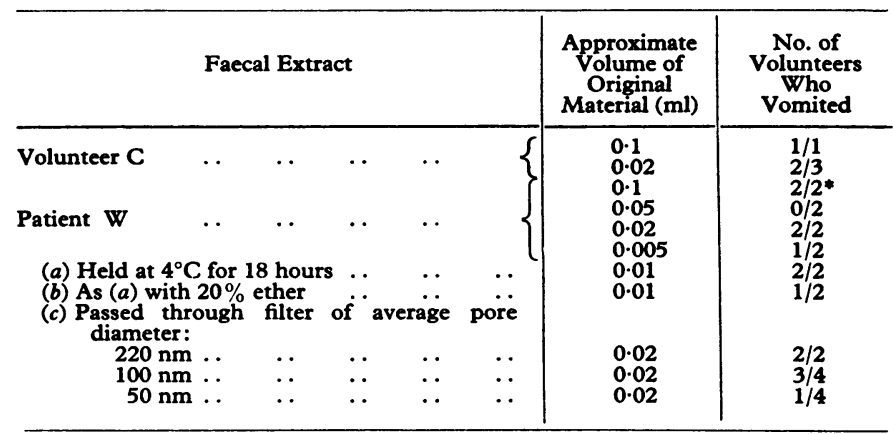

*Both these volunteers were inoculated in 1964 in Bristol. One received the resuspended pellet from extract centrifuges at 35,000 r.p.m. for two hours. The other
was volunteer $C$. 


\section{Propagation of the Guildford Agent}

We also report briefly here the results of laboratory studies of three outbreaks of gastroenteritis in 1964 in the Guildford area (Table IV). A cytopathic agent was recovered from 9 out of 14 throat swabs and from 11 out of 30 faeces from acute phase

TABLE IV-Results of Examination of Throat and Faeces Specimens on WI-38 Cells

\begin{tabular}{|c|c|c|c|c|c|}
\hline \multirow{2}{*}{ Outbreak } & \multirow{2}{*}{$\begin{array}{c}\text { No. of } \\
\text { Cases } \\
\text { Examined }\end{array}$} & \multicolumn{2}{|c|}{ Throat Swabs } & \multicolumn{2}{|c|}{ Faeces Specimens } \\
\hline & & $\begin{array}{c}\text { No. } \\
\text { Examined }\end{array}$ & $\begin{array}{l}\text { No. } \\
\text { Positive }\end{array}$ & $\begin{array}{c}\text { No. } \\
\text { Examined }\end{array}$ & $\begin{array}{c}\text { No. } \\
\text { Positive }\end{array}$ \\
\hline \multicolumn{6}{|c|}{ Autumn 1964 Outbreaks } \\
\hline $\begin{array}{l}\cdots \\
\cdots\end{array}$ & $\begin{array}{c}12 * \\
26 \\
5\end{array}$ & $\begin{array}{l}6 \\
3 \\
5\end{array}$ & $\begin{array}{l}5 \\
2 \\
2\end{array}$ & $\begin{array}{r}7 \\
23 \\
-\end{array}$ & $\begin{array}{r}3 \\
8 \\
-\end{array}$ \\
\hline Total & 43 & 14 & 9 & 30 & 11 \\
\hline \multicolumn{6}{|c|}{ February 1966 Hospital Outbreak } \\
\hline & 6 & 6 & 2 & 2 & 2 \\
\hline $\begin{array}{l}\text { Total for } \\
1964 \text { and } \\
1966\end{array}$ & 49 & 20 & 11 & 32 & 13 \\
\hline
\end{tabular}

*From one case both throat and faeces specimens were examined, and both were bositive. specimens from patients with other diseases were inoculated into similar cultures with negative results.

cases, but from none out of 220 patients with other diseases inoculated into similar cultures at the same time. The agent produced a progressive cytopathic effect, resembling that due to picornaviruses, in WI-38 cells rolled at $33^{\circ} \mathrm{C}$ and was seen only after at least one blind passage of cells and supernatant medium. The effect was seen only if cells were maintained in serum-free medium, and was inhibited by human, rabbit, and calf serum. The agent had no effect on monkey kidney or HeLa cells. It was acid-stable, ether-stable, and bile-stable and inactivated at $50^{\circ} \mathrm{C}$ for 30 minutes. It passed a $450-\mathrm{nm}$ filter, was unaffected by tetracycline, and was not neutralized by serum against echoviruses 1-33, polioviruses 1-3, Coxsackie $B$ viruses 1-6, and Coxsackie A viruses 9,7 , and 21 , used at 50 times the dilution needed to neutralize $100 \mathrm{TCD}_{50}$ of the homologous virus. Twofold to threefold rising titres of neutralizing antibody were detected in the sera of three patients.

The basic properties of this agent were confirmed in two other laboratories. However, for no discovered reason the virus could not later be reisolated from the original specimens and after some years laboratory strains no longer produced a cytopathic effect in WI-38 cells of many passage levels. A virus passed 20 times was given to two volunteers and produced no symptoms. Similar agents were isolated from a hospital outbreak in 1966 (Table IV).

\section{Attempts to Propagate the W Agent}

Extracts of faeces from Volunteer $C$ which had proved to be infectious for other volunteers produced no cytopathic effect after two to five passages in human embryo trachea organ cultures or in the following cultures of human cells: WI-38, HEL-7, HeLa, human embryo kidney, primary human embryo fibroblast, AC and WISH lines of human amnion, Detroit 98, L132, J-111, and Intestine 407. Cells of other species-RK13 rabbit cells, V3 monkey cells, BHK 21 hamster cells, McCoy cells (now known to be mouse), MDBK bovine cells, and PT$\mathrm{K}-1$ potoroo kidney cells-also gave negative results. In WI-38 cultures there was no cytopathic effect, nor were there inclusions, haemadsorption, haemagglutination, and interference with growth of E.C.H.O. 11 virus after incubation in a range of maintenance media with or without sera at various temperatures and pHs (Egglestone, 1968).

It was thought that the virus might be an obligate parasite of human intestinal epithelium. Attempts to propagate it in human embryo intestinal organ cultures in 1966 produced no evidence of growth of the agent (Egglestone, 1968). In later experiments organ cultures of human embryonic oesophagus, ileum, and colon were prepared as described by Rubenstein and Tyrrell (1970). The cultures were inoculated with $0.1 \mathrm{ml}$ of faecal emulsion, incubated for three hours and then washed. The medium was changed and harvested daily for five days. The stored media were thawed when volunteers were available, pooled, and were given orally as described above. The results are shown in Table II, line D. One of the 20 volunteers who were inoculated vomited once, and another had diarrhoea and fever which were apparently significant. Both inocula came from cultures of oesophagus, but it is necessary to point out that one of the 12 volunteers given control inocula had this degree of fever and two had diarrhoea motions.

Experiments have now been reported in which a strain of human gastroenteritis virus has apparently been propagated in organ cultures of human ileum (Dolin et al., 1971). We were kindly supplied with a pool of faecal filtrate of this, the Norwalk agent, and tried to propagate it, using the culture technique described by the authors. A volunteer given a pool of fluids harvested on days $1,3,4$, and 5 after inoculation developed illness exactly like that produced by agent $W$; however, a typical illness also occurred in another volunteer who was given pooled fluids from dishes which contained no tissue but which received the same inoculum in the same experiment. We presume that this was due to residual virus from an inoculum of particularly high titre. When the fluids harvested from this same experiment on the fourth day after inoculation were each given to one volunteer, neither developed symptoms. We have therefore no evidence that the Norwalk agent multiplied in the cultures.

\section{Discussion}

Winter vomiting disease was first described in the U.S.A. (Zahorsky, 1929) but it has been recognized in Britain for many years (Gray, 1939; Bradley, 1943).

Failure to isolate a bacterium is poor evidence that the disease is due to a virus, and many unpublished attempts to isolate viruses in outbreaks have been unsuccessful or have yielded "passenger" viruses, such as adenovirus type 1, which was found in one boy at the school we studied. The syndrome of nonbacterial gastroenteritis in small children may well be due to a similar agent, and adenoviruses and enteroviruses have been isolated from such patients; however, parallel studies of unaffected children show similar viruses in similar frequencies and these are apparently, in most cases, "passengers" also. Our results confirm those of Reimann et al. (1945), Gordon et al. (1947), Jordan et al. (1953), Adler and Zickl (1969), and Dolin et al. (1971), that faeces may contain viral agents which cause gastroenteritis in volunteers, but this is the first demonstration of such an agent in Britain, and the second in a school outbreak. It is noteworthy that the essential features of the epidemic disease-that is, the short incubation period and the presence of vomiting, diarrhoea, and low fever-were all reproduced in volunteers. Nevertheless many illnesses are so mild that care is needed to distinguish them from the symptoms of uninoculated volunteers. The disease produced by an American agent showed the same clinical features.

It is important also that the $W$ agent seems to be small and ether-stable and therefore might be related to the picornaviruses which include many inhabitants of the gastrointestinal tract. It is also possible that the Guildford agent may in fact have been the cause of the disease in the patients from which it was isolated and that it may share properties in common with the $W$ agent. Although we shall never know whether it did cause disease in Guildford the results of the studies are worth recording in case it turns out later, as happened with the D.C. strain of rhinovirus, that some of the details of the propagation 
method used were important elements of later, more generally successful methods (Conant et al., 1968).

This paper is a report to the Public Health Laboratory Service Working Party on Epidemic Non-bacterial Gastroenteritis.

We wish to thank Dr. T. A. A. Hunter, Medical Officer, Marlborough College, for his invaluable work in documentation of the principal epidemic described and the collection of specimens. We should also like to thank the volunteers for their willing help, Miss J. M. Bailey, S.R.N., for nursing assistance, and numerous other colleagues for help in the laboratory work.

Some of this work was supported by a grant from the Department of Health and Social Security.

Requests for reprints should be sent to: Dr. S. K. R. Clarke, Public Health Laboratory, Kingsdown, Bristol BS2 8EL.

\section{References}

Adler, J. L., and Zickl, R. (1969). Journal of Infectious Diseases, 119, 668. Bradley, W. H. (1943). British Medical Journal, 1, 309.

Conant, R. M., Hamparian, V. V., Stott, E. J., and Tyrrell, D. A. J. (1968) Nature, 217,1264

Dolin, R., et al. (1971). Journal of Infectious Diseases, 123, 307.

Egglestone, S. I. (1968). Ph.D. Thesis, University of Bristol.

Gordon, I., Ingraham, H. S., and Korns, R. F. (1947). Fournal of Experimental Medicine, 86, 409.

Gray, J. D. (1939). British Medical fournal, 1, 209.

Jordan, W. S., Gordon, I., and Dorrance, W. R. (1953). Fournal of Experimental Medicine, 98, 461.

Reimann, H. A., Price, A. H., and Hodges, J. H. (1945). Proceedings of the Society for Experimental Biology and Medicine, 59, 8.

Rubenstein, D., and Tyrrell, D. A. J. (1970). British fournal of Experimental Pathology, 51, 210.

Zahorsky, J. (1929). Archives of Pediatrics, 46, 391.

\section{PRELIMINARY COMMUNICATIONS}

\section{Autonomic Disturbance at Onset of Acute Myocardial Infarction}

\section{S. W. WEBB, A. A. J. ADGEY, J. F. PANTRIDGE}

British Medical fournal, 1972, 3, 89-92

\section{Summary}

Of 74 patients seen within 30 minutes of the onset of acute myocardial infarction $68(92 \%)$ had signs of autonomic imbalance. Excessive vagal activity was evident in $41(55 \%)$ and there was sympathetic overactivity in $27(36 \%)$. The high incidence of sudden death in the acute phase of a coronary attack probably results from the electrical imbalance caused by autonomic disturbance. This disturbance must therefore be taken into account in any prophylactic regimen against the lethal early ventricular dysrhythmias.

\section{Introduction}

Most deaths from acute myocardial infarction occur within one hour of the onset of symptoms (Fulton et al., 1969), and the median of the period between onset and admission to hospital is more than eight hours (McNeilly and Pemberton, 1968). Attention has therefore been directed to the prehospital phase of the acute coronary attack (Pantridge and Geddes, 1966, 1967). Ventricular fibrillation occurs most often immediately after the onset of acute myocardial infarction and is the cause of most deaths (Pantridge and Geddes, 1967; Pantridge and Adgey, 1969). Understanding the factors that initiate ventricular fibrillation may enable us to prevent it.

Self-injection of atropine and lignocaine has been advocated as a way of reducing the prehospital mortality in coronary attacks (Levine, 1969; Sarnoff, 1970; Friedberg, 1972; Yu, 1972). It therefore seems important to know the incidence of autonomic disturbance and to assess the effects of these drugs in treating it. We have recorded data on 558 patients seen within one hour of the onset of acute infarction and in most cases managed by a mobile coronary care unit. The last 200 of them

Cardiac Department, Royal Victoria Hospital, Belfast

S. W. WEBB, B.SC., M.R.C.P., Research Fellow

A. A. J. ADGEY, M.R.C.P., Physician

J. F. PAANTRIDGE, M.D., F.R.C.P., Physician-in-charge were studied by a continuous recording of the cardiogram and frequent recordings of the blood pressure. The observer, usually one of us (S.W.W.), was confident that in 88 of these 200 patients the interval between the onset of symptoms and the start of observation was less than 30 minutes.

This communication deals with these 88 patients ( 81 men and 7 women), all of whom fulfilled the criteria for indubitable infarction previously described (Adgey et al., 1968; Adgey et al., 1971).

\section{Patients}

The mean age of the 81 men was 56 years and that of the seven women 63 years. Forty-two patients had anterior infarction, 44 posterior infarction, and two anterior subendocardial infarction. Thirty-four $(39 \%)$ had had a previous infarct. Thirteen $(15 \%)$ had ventricular fibrillation when first seen and were therefore excluded from the study of autonomic disturbance. Another patient was excluded because of the possibility of previous hypertension.

In the remaining 74 patients the heart rate and rhythm and the blood pressure were observed immediately the patient was seen and before analgesic or other therapy. None of the patients had been taking beta-blocking drugs, digitalis, or hypotensive agents.

Patients with sinus tachycardia (heart rate of 100 or more) with or without transient hypertension were considered to show sympathetic overactivity. Transient hypertension (blood pressure of $160 / 100 \mathrm{~mm} \mathrm{Hg}$ or higher) in the absence of sinus tachycardia was also regarded as evidence of sympathetic overactivity, since a reflex sympathetic pressor response with minimal alteration in the heart rate has been described (Malliani et al., 1969; Peterson and Brown, 1971). Patients who had sinus bradycardia (heart rate of 60 or less) or atrioventricular block (second-degree or complete) were considered to show parasympathetic overactivity, as also were those with transient hypotension (systolic blood pressure $100 \mathrm{~mm} \mathrm{Hg}$ or lower) in the absence of pronounced bradycardia.

\section{Incidence of Autonomic Disturbance}

The incidence of autonomic disturbance at the initial observation is shown in Fig. 1. Only six patients ( $8 \%$ ) had a normal heart rate and normal blood pressure. Twenty-seven patients $(36 \%)$ showed evidence of sympathetic overactivity. Seventeen of them had sinus tachycardia, accompanied in nine by hypertension, and 10 had transient hypertension with a heart rate in the normal range. 